\title{
Congenital ventricular septal defects and prenatal exposure to cyclooxygenase inhibitors
}

\author{
F. Burdan ${ }^{1}$, J. Szumilo², \\ J. Dudka², A. Korobowicz ${ }^{3}$ \\ and R. Klepacz ${ }^{2}$
}

\author{
${ }^{1}$ Experimental Teratology Unit, Human Anatomy Department, \\ ${ }^{2}$ Clinical Pathomorphology Department, \\ 3Pediatric Pulmonology and Rheumatology Department, \\ Medical University of Lublin, Lublin, Poland
}

\section{Correspondence \\ F. Burdan \\ Experimental Teratology Unit Human Anatomy Department \\ Medical University of Lublin \\ 4 Jaczewskiego Str. \\ PL-20090 Lublin \\ Poland \\ Fax: + 48-81-532-8903 \\ E-mail: fb3@wp.pl \\ Research supported by the Polish Committee of Scientific Research (Grant KBN 3 P05A 04825 to \\ F. Burdan).}

Received O ctober 26, 2005 Accepted April 5, 2006

\section{Abstract}

Ventricular septal defects (VSDs) are common congenital abnormalities which have been reported to be associated with maternal fever and various environmental factors. The aim of the present study was to evaluate the effect of prenatal exposure to cyclooxygenase (COX) inhibitors on heart defects. A retrospective statistical analysis was performed using data collected in our laboratory during various teratological studies carried out on albino CRL:(WI)WUBR Wistar strain rats from 1997 to 2004. The observations were compared with concurrent and historic control data, as well as findings from other developmental toxicological studies with selective and nonselective COX-2 inhibitors. Despite the lack of significant differences in the frequency of VSDs between drug-exposed and control groups, statistical analysis by the two-sided Mantel-Haenszel test and historical control data showed a higher incidence of heart defects in offspring exposed to nonselective COX inhibitors $(30.06 / 10,000)$. Unlike other specific inhibitors, aspirin (46.26/10,000) and ibuprofen (106.95/ $10,000)$ significantly increased the incidence of the VSD when compared with various control groups (5.38-19.72/10,000). No significant differences in length or weight were detected between fetuses exposed to COX inhibitors and born with VSD and non-malformed offsprings. However, a statistically significant increase of fetal body length and decrease of body mass index were found in fetuses exposed to COX inhibitors when compared with untreated control. We conclude that prenatal exposure to $\mathrm{COX}$ inhibitors, especially aspirin and ibuprofen, increased the incidence of VSDs in rat offspring but was not related to fetal growth retardation.

\section{Introduction}

Ventricular septal defects (VSDs) are the most common cardiac congenital anomalies (1-3). Their incidence ranges from 3 to 56 per 1000 newborns (2) depending on the

\section{Key words}

- Cyclooxygenase

- Cyclooxygenase inhibitor

- Nonsteroidal

anti-inflammatory drug

- Ventricular septal defect screening methods used. Anatomically, these anomalies are divided into defects of the membranous or muscular part of the interventricular cardiac septum. In some cases the absence of both parts of the septum is observed that commonly coexists with addi- 
tional cardiovascular anomalies, e.g., aortic hypoplasia and transposition of large arteries $(3,4)$. Observations in humans $(4,5)$ and animals $(6,7)$ have revealed that, unlike small defects which may close spontaneously postnatally, major VSDs need various medical treatments.

The etiology of these malformations is still unclear. It is estimated that in $4 \%$ of cases a chromosomal or genetic defect exists $(1,8)$. A role of environmental and chemical factors has also been suggested (9). In addition, a review of the literature shows that various maternal diseases, e.g., diabetes mellitus, infections, fever, as well as the treatment applied, may induce VSDs (1$3,9,10)$. It has been emphasized that prenatal exposure to cyclooxygenase (COX) inhibitors increases the risk of septal defects $(2,11$ 19). However, the dependence of these defects on maternal COX inhibitor exposure has never been fully confirmed.

COX inhibitors are the drugs most commonly ingested during pregnancy (20). The group includes all the nonsteroidal anti-inflammatory drugs (NSAIDs), as well as COX inhibitors without anti-inflammatory activity, e.g., paracetamol (acetaminophen) and propyphenazone, which are used as popular analgesics and antipyretics. Depending on the country, some of these (aspirin, diclofenac, ibuprofen, paracetamol, propyphenazone, naproxen) are available without prescription (over-the-counter) and are used for self-medication (21). For an increased therapeutic effect, NSAIDs are sold in mixed formula preparations that include also one of the following substances: caffeine, codeine or pseudoephedrine. Paracetamol, as a centrally active substance, could be mixed with other peripherally active COX inhibitors. However, such combinations are prohibited in some countries (22).

According to their selectivity for both constitutive (COX-1) and induced (COX-2) isoenzymes, these drugs are divided into: selective COX-1 inhibitors (low doses of aspirin), nonselective COX inhibitors (traditional NSAIDs, propyphenazone), preferential COX-2 inhibitors (e.g., meloxicam), and selective COX-2 inhibitors (e.g., celecoxib, rofecoxib, valdecoxib, DFU, DuP-697) (23). Due to the increased risk of cardiovascular complications, the selective COX-2 inhibitors were withdrawn from the market or their therapeutic use was limited (16). It is worth mentioning that the COX-3 isoenzyme, recently found in the central nervous system is selectively inhibited by paracetamol (16).

The present paper reports a summary of findings collected at the Experimental Teratology Unit of the Medical University of Lublin during various developmental toxicological studies on the effect of selective and non-selective COX-2 inhibitors in the years 1997-2004. The aim of the study was to evaluate the incidence of ventricular septal defects in COX inhibitor-exposed animals.

\section{Material and Methods}

All studies were carried out on albino CRL:(WI)WUBR Wistar rats according to the guidelines of the Local Bioethics Committee. Animals were obtained from a commercial breeder (Rembertow, Warsaw, Poland) and kept under standard laboratory conditions as previously described (24-27). The initial body weight of the dams on insemination day (gestational day 1, GD 1), ranged from 200 to $250 \mathrm{~g}$. Commercial laboratory rat chow (LSM ${ }^{\circledR}$; Agropol, Motycz, Poland) and filtered municipal tap water (Lublin, Poland) were provided ad libitum. All dams were intragastrically exposed to various selective, i.e., DuP-697 (5-bromo-2(4-fluorophenyl)-3-[4-(methylsulfonyl)phenyl]-thiophene) (24), DFU (5,5-dimethyl3-(3-fluorophenyl)-4-(4-methylsulfonyl) phenyl-2(5H)-furanone) (16), and non-selective COX-2 inhibitors, i.e., ibuprofen(15), paracetamol (25), piroxicam (16), propyphenazone (26), and tolmetin (15) with or 
without caffeine (25,27-29). Detailed characteristics of all treated groups are presented in Table 1. All compounds were administered separately or together with caffeine ground in Tween $80(0.11 \mathrm{~g} / \mathrm{dose})$ and diluted in distilled water. The administration period was different in various studies but always covered the early organogenesis which occurs on GD 7-16 in rats. The animals in the corresponding control groups (historical control) received the Tween 80 water suspension in volumes corresponding to those given to the drug-treated groups (10 $\mathrm{mL} / \mathrm{kg}$ body weight). Pregnancies were terminated on the GD 21 by cesarean section and comprehensive clinical maternal measurements were made (30). The activity of alanine aminotransferase and aspartate aminotransferase, as well as urea and total protein level, were determined in maternal blood serum for selected drugs. Fetuses were removed, separated from the placenta, sexed and routinely examined macroscopically. The weight of fetuses and placentas, and the fetal crown-rump length were checked. The body mass index (BMI) and pre- and postimplantation mortality (loss) were calculated. One third of the randomly selected fetuses were dissected in situ or stained with Bouin solution and internally examined by the method of Wilson with our modifications (see Ref. 30). The remaining fetuses were eviscerated and used for the skeletal examination. The eviscerated organs were also examined. However, for the final analysis only the heart dissected during in situ preparation or examined according to Wilson's method, as well as the corresponding fetal data, were included. Based on present terminology (31), all findings were classified as variations or malformations.

In contrast to typical teratology studies all fetuses were analyzed individually. The drug-exposed offsprings were divided into three groups: I) fetuses with VSDs (VSD group), II) fetuses without any external or internal congenital malformations (COX group), and III) fetuses with congenital malformation other than VSDs. Due to the wide spectrum of malformations, fetuses from group III were not included in the final statistical analysis. Untreated offsprings without any malformations were pooled into control group.

The unit for a statistical measurement was a single fetus. Homogeneity of distribution was examined using the KolmogorowSmirnow test. Due to non-homogeneous distribution of the untreated control group the Mann-Whitney U-test was used to analyze statistical differences in fetal growth parameters. To determine differences in the incidence of VSDs between the results obtained here and concurrent meta-analysis data presented by Cook et al. (17) the two-sided Mantel-Haenszel test was employed. The level of significance was set at $\mathrm{P}<0.05$ in all analyses.

\section{Results}

Of the 6744 liveborn fetuses prenatally exposed to various COX inhibitors in our laboratory, 1369 were dissected in situ or examined internally by the method of Wilson. VSDs were observed only in 6 rat fetuses exposed exclusively to nonselective COX inhibitors such as aspirin, ibuprofen, piroxicam, and tolmetin (Table 1). In all cases the defect was limited to the membranous part of the septum. A single case of VSD was found in the untreated control group $(\mathrm{N}=198)$.

A significant increase of fetal body weight and a secondary decrease of BMI were found in the group of fetuses prenatally exposed to COX inhibitors when compared with untreated control (Table 2). Mean body weight, crown-rump length and BMI were higher in the group of fetuses born with VSD. In all cases, fetal weight and length were included in the 5-95\% confidence interval in the nonmalformed COX inhibitor-exposed control (Figures 1 and 2). However, no statistically 
significant differences were found when the two groups were compared (Table 2). A highly significant $(\mathrm{P}<0.01)$ correlation between fetal length and weight was observed in the non-malformed group (Figure 3). Similar to the untreated control group $(\mathrm{P}=0.0598)$, this correlation was nonsignificant $(\mathrm{P}=0.5441)$ in the group of fetuses born with VSD.
Two cases of VSDs observed in the group exposed to ibuprofen and a single case from the tolmetin group were found in the litters in which post-implantation mortality and clinical signs of maternal toxicity occurred (data not shown). Furthermore, in these litters the values of the evaluated biochemical parameters were not within the 5-95\% confi-

Table 1. Incidence of ventricular septal defects (VSD) in rat fetuses exposed to nonselective COX inhibitors or their analgesic combinations and selective COX-2 inhibitors.

\begin{tabular}{|c|c|c|c|c|}
\hline Agents (references) & $\begin{array}{l}\text { Treatment } \\
\text { period (days) }\end{array}$ & $\begin{array}{c}\text { Dose } \\
\left(\mathrm{mg} \mathrm{kg}^{-1} \text { day-1 }^{-1}\right)\end{array}$ & $\begin{array}{l}\text { Fetuses } \\
\text { examined }\end{array}$ & VSD \\
\hline \multicolumn{5}{|l|}{ Non-selective COX inhibitors } \\
\hline Aspirin & $8-21$ & 175 & $35(146 / 12)$ & 2 \\
\hline \multirow[t]{3}{*}{ Propyphenazone (26) } & $8-14$ & 2.1 & $30(178 / 10)$ & 0 \\
\hline & & 21 & $39(229 / 16)$ & 0 \\
\hline & & 210 & $41(170 / 10)$ & 0 \\
\hline \multirow[t]{3}{*}{ Paracetamol (25) } & $8-14$ & 3.5 & $45(190 / 13)$ & 0 \\
\hline & & 35 & $40(194 / 13)$ & 0 \\
\hline & & 350 & $25(171 / 10)$ & 0 \\
\hline \multirow[t]{3}{*}{ Paracetamol:caffeine (27) } & $8-14$ & $3.5: 0.7$ & $32(169 / 12)$ & 0 \\
\hline & & $35: 7$ & $41(211 / 15)$ & 0 \\
\hline & & $350: 70$ & $23(183 / 13)$ & 0 \\
\hline \multirow[t]{3}{*}{ Propyphenazone:caffeine (29) } & $8-14$ & 2.1:0.7 & $27(180 / 12)$ & 0 \\
\hline & & $21: 7$ & $24(166 / 12)$ & 0 \\
\hline & & $210: 70$ & $26(203 / 14)$ & 0 \\
\hline \multirow[t]{3}{*}{ Paracetamol:propyphenazone (29) } & $8-14$ & $3.5: 2.1$ & $22(181 / 13)$ & 0 \\
\hline & & $35: 21$ & $40(236 / 17)$ & 0 \\
\hline & & $350: 210$ & $13(163 / 12)$ & 0 \\
\hline \multirow[t]{3}{*}{ Paracetamol:propyphenazone:caffeine (28) } & $8-14$ & $3.5: 2.1: 0.7$ & $57(260 / 19)$ & 0 \\
\hline & & $35: 21: 7$ & $49(210 / 16)$ & 0 \\
\hline & & $350: 210: 70$ & $68(221 / 15)$ & 0 \\
\hline \multirow[t]{3}{*}{ Ibuprofen (15) } & $8-21$ & 25.5 & $54(252 / 20)$ & 0 \\
\hline & & 255 & $43(195 / 16)$ & 2 \\
\hline & & 600 & $12(71 / 6)$ & 0 \\
\hline \multirow{3}{*}{ Tolmetin (15) } & $8-21$ & 25.5 & $55(247 / 20)$ & 0 \\
\hline & & 255 & $49(213 / 17)$ & 0 \\
\hline & & 2550 & $7(38 / 4)$ & 1 \\
\hline \multirow[t]{3}{*}{ Piroxicam (16) } & $8-21$ & 0.3 & $49(242 / 20)$ & 0 \\
\hline & & 3 & $46(223 / 18)$ & 1 \\
\hline & & 30 & $25(124 / 11)$ & 0 \\
\hline \multicolumn{5}{|l|}{ Selective COX-2 inhibitors } \\
\hline \multirow[t]{3}{*}{ DFU (16) } & $8-21$ & 0.2 & $55(251 / 20)$ & 0 \\
\hline & & 2 & $48(240 / 20)$ & 0 \\
\hline & & 20 & $53(251 / 20)$ & 0 \\
\hline \multirow[t]{3}{*}{ DuP-697 (24) } & $7-17$ & 0.05 & $65(245 / 17)$ & 0 \\
\hline & & 3.5 & $67(247 / 17)$ & 0 \\
\hline & & 35 & $64(244 / 17)$ & \\
\hline Total & & & $1369(6744 / 497)$ & 6 \\
\hline
\end{tabular}

Aspirin was used as the positive control. Fetuses examined for visceral malformations (No. of all fetuses/No. of litters). Aspirin data were not included in the final statistical evaluation because it did not meet the requirements published by Cook et al. (17). For propyphenazone and paracetamol, 5 extra litters were later added to each experimental group to evaluate cartilage development. 

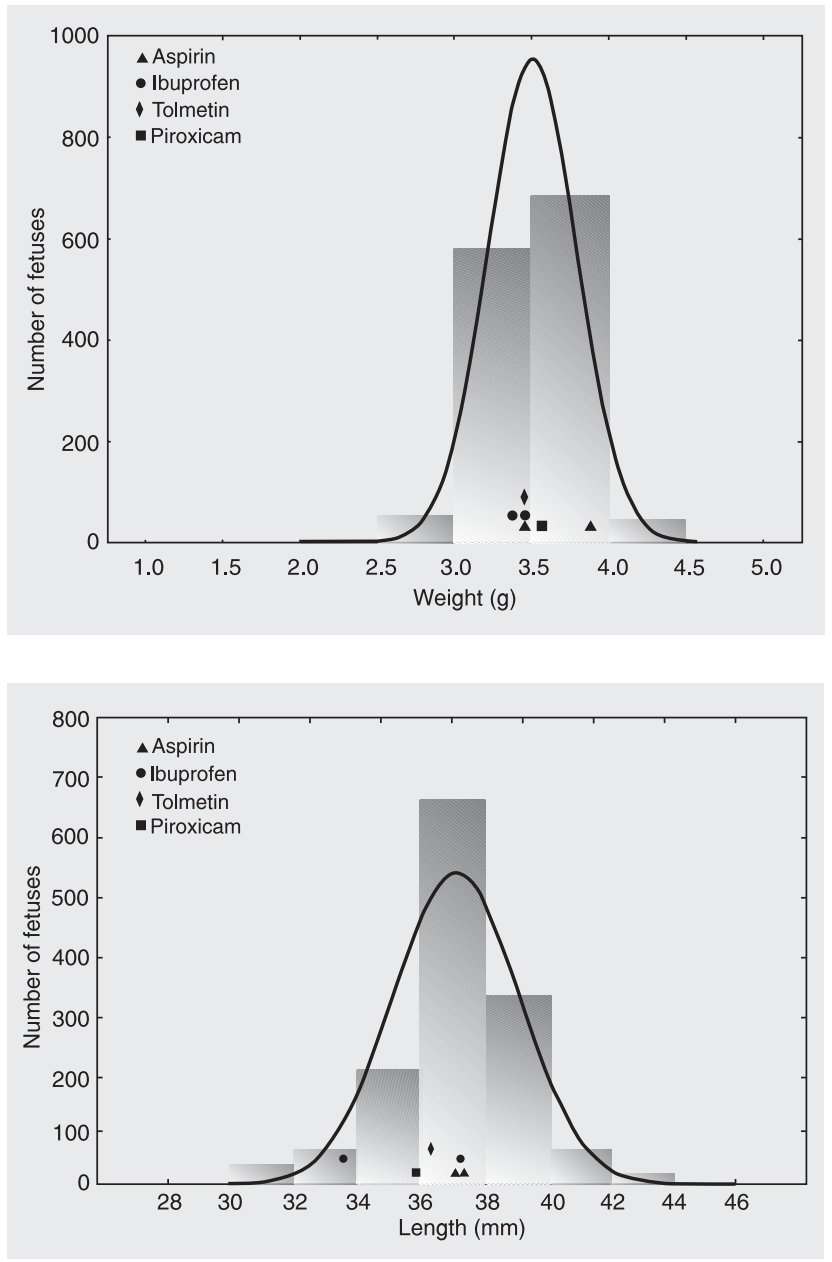

Figure 1. Weight of 21-day-old rat fetuses prenatally exposed to COX inhibitors. Each symbol indicates a single fetus with a ventricular septal defect exposed to the corresponding substance examined.

Figure 2. Crown-rump length of 21-dayold rat fetuses prenatally exposed to cyclooxygenase inhibitors. Each symbol indicates a single fetus with a ventricular septal defect exposed to the corresponding substance examined.

Table 2. Developmental parameters of untreated control rat fetuses ( $C O N ; N=198)$, fetuses without any internal congenital malformations ( $C O X ; N=1363$ ) and offspring born with ventricular septal defects (VSD; $\mathrm{N}=6$ ) in groups prenatally exposed to various COX inhibitors.

\begin{tabular}{|c|c|c|c|c|}
\hline & Min & Max & Mean \pm SD & Median \\
\hline \multicolumn{5}{|c|}{ Fetal weight (g) } \\
\hline $\mathrm{CON}$ & 2.78 & 5.40 & $3.53 \pm 0.35$ & 3.50 \\
\hline $\operatorname{cox}$ & 1.64 & 4.45 & $3.49 \pm 0.29$ & 3.53 \\
\hline VSD & 3.39 & 3.81 & $3.53 \pm 0.14$ & 3.48 \\
\hline \multicolumn{5}{|c|}{ Fetal length (mm) } \\
\hline $\mathrm{CON}$ & 36.08 & 37.48 & $36.82 \pm 0.40$ & 36.84 \\
\hline $\operatorname{cox}$ & 30.15 & 44.17 & $37.13 \pm 1.99 *$ & 37.20 \\
\hline VSD & 33.62 & 37.47 & $36.37 \pm 1.48$ & 36.87 \\
\hline \multicolumn{5}{|c|}{ Body mass index $\left(\mathrm{kg} / \mathrm{m}^{2}\right)$} \\
\hline CON & 2.11 & 4.15 & $2.61 \pm 0.27$ & 2.59 \\
\hline $\operatorname{cox}$ & 1.50 & 4.11 & $2.55 \pm 0.29 *$ & 2.53 \\
\hline VSD & 2.44 & 3.07 & $2.68 \pm 0.23$ & 2.66 \\
\hline
\end{tabular}

Min = minimum value; $M a x=$ maximum value; $S D=$ standard deviation.

*P $<0.05$ compared to control (Mann-Whitney U-test). 


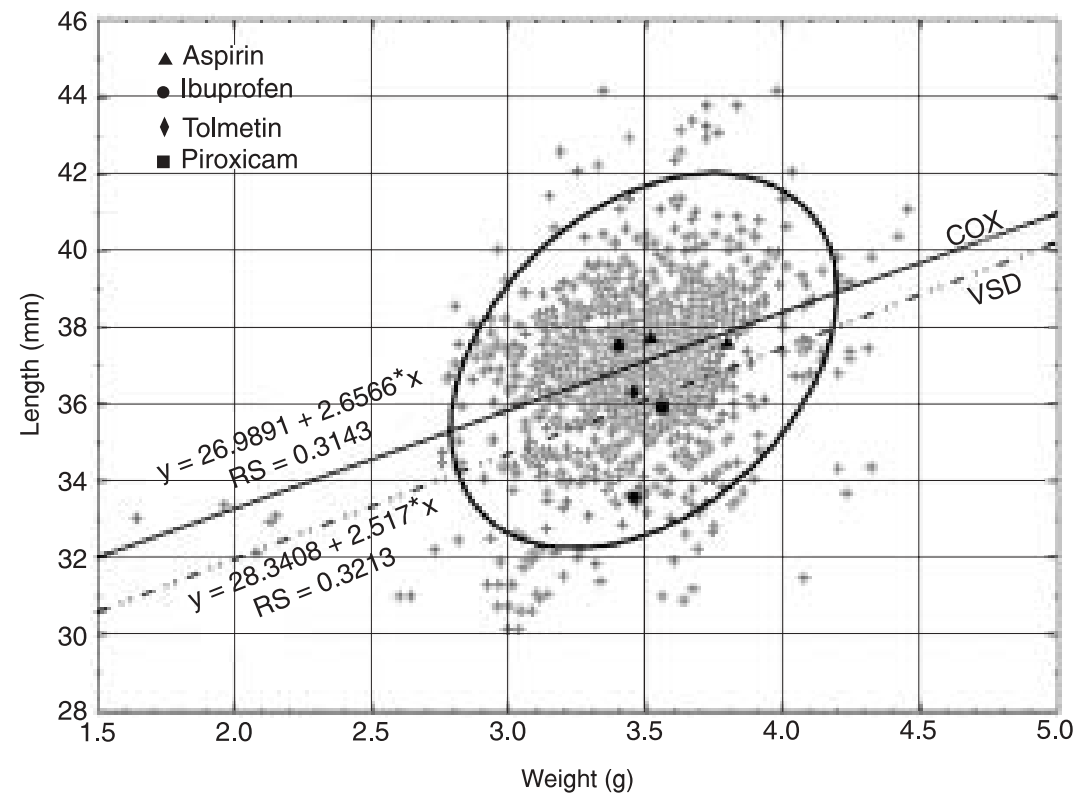

Figure 3. Correlation between fetal weight and length of rat fetuses prenatally exposed to cyclooxygenase (COX) inhibitors. Each symbol indicates a single fetus with a ventricular septal defect (VSD) exposed to the corresponding substance examined. Regression equation and Spearman rank R (RS) for malformed and non-malformed offspring are presented on the corresponding regression line.

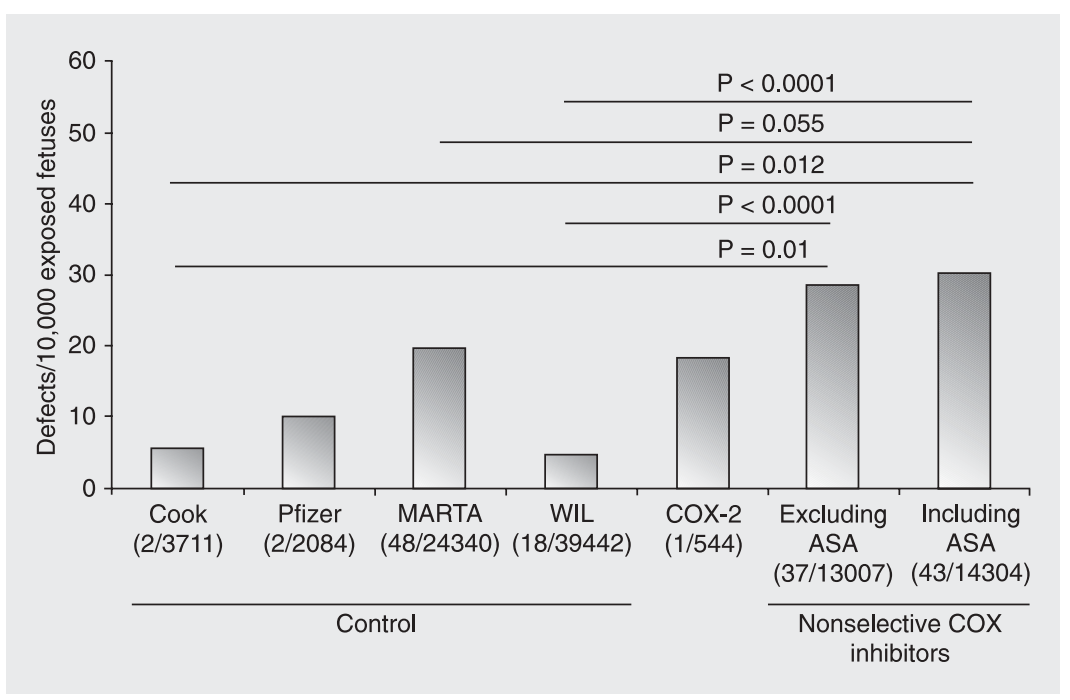

Figure 4. Incidence of ventricular septal defects in various historical control groups and groups prenatally exposed to selective cyclooxygenase (COX)-2 inhibitors, and nonselective COX inhibitors in relation to aspirin (ASA). Pfizer, Middle Atlantic Reproduction and Teratology Association (MARTA) and WIL Research Laboratories, Inc. (WIL) control data are those reported by Cook et al. (17) and were not obtained directly from these sources. Data for selective COX-2 inhibitors include: DFU (16), DuP-697 (24) and CJ -19,209 (19). Data for nonselective COX inhibitors contain our own (Table 1) and Cappon et al. (19) findings, and all previous observations summarized by Cook et al. (17). The ratio (fetuses affected/total fetuses examined) is listed, with the source or drug group on the abscissa. Data were analyzed statistically by the two-sided Mantel-Haenszel test. dence interval of the corresponding values for the COX inhibitor-exposed or untreated groups. No statistically significant difference in maternal body weight gain during pregnancy was noted between the two groups of fetuses exposed to COX inhibitors (COX vs VSD).

The pooled statistical analysis of our own data and concurrent data for the COX inhibitors with high anti-inflammatory activity reported by Cook et al. (17) and Cappon et al. (19) revealed that only nonselective compounds (as a group of drugs) increased the risk of VSD in rat fetuses (Figure 4). The highest expected ratio was found for ibuprofen (106.95/10,000 exposed fetuses) and aspirin $(46.26 / 10,000)$. For both drugs the incidence was higher when compared with the control data reported in the studies of Pfizer (9.59/10,000), Middle Atlantic Reproduction and Teratology Association (19.72/ 10,000), WIL Research Laboratories, Inc. (4.56/10,000), and Cappon et al. (5.38/ 10,000) (19). However, no statistically significant differences were found between these two drugs $(\mathrm{P}=0.1210)$. A lower ratio was calculated for the nonselective COX inhibitors, when aspirin was excluded (28.45/ $10,000)$ or included $(30.06 / 10,000)$, and for the selective COX-2 inhibitors (18.38/ $10,000)$.

\section{Discussion}

The present study revealed a higher incidence of VSDs in rat fetuses prenatally exposed to various COX inhibitors. The highest toxic effects were found for ibuprofen and aspirin. This new grading of both drugs was possible due to new data which were not included in Cook's analysis (17). It is worth mentioning that none of the available papers proved the cardiac prenatal toxicity of a single COX inhibitor in in vivo animal studies. However, a nonsignificant increase in VSDs, as well as in other congenital anomalies, was observed (15-19). This was a con- 
sequence of the small number of cardiac abnormalities and incidental character of those changes in the corresponding control groups, a fact that makes statistical analysis difficult or impossible (32). Based on our ibuprofen observations, we suggest that other COX inhibitors, including selective and nonselective compounds, may have similar or even higher developmental toxic cardiac effects. Findings from a limited number of studies, one in particular (17), are not sufficient to draw reliable final conclusions about the target organ toxicity.

The results may also be influenced by the dose level and rat strain used in the studies from various laboratories. Regarding ibuprofen, tolmetin and piroxicam, dose dependency is likely since the VSDs were observed in the litters exposed to doses over the non-observed toxic level for each compound. However, this effect was not observed by Cook et al. (17). Because of the low incidence of cardiac defects and large number of various rat stocks used to evaluate the prenatal toxicity of COX inhibitors, the influence of animal strains is difficult to prove. On the other hand, the differences in the incidence of developmental malformations or variations have been confirmed in different stocks or strains of laboratory animals. For example, asymmetrical vertebrae were observed in $3 \%$ of untreated OsborneMendel rats and only in $0.6 \%$ of Wistar rats (33). A lower incidence of this anomaly was detected in Charles River CD-1 mice but not in a population of NMRI mice. Since our studies were performed on the same strain of albino CRL:(WI)WUBR Wistar rats and because of the low number of defects, the different sensitivity of other rat strains should be considered as a potential factor that may modify the developmental tolerability of COX inhibitors.

Unlike in the analogue midline defect (MD) study (34), no correlation between fetal growth and VSDs was found here. The weight and length of all the malformed fe- tuses corresponded to the 5-95\% confidence interval for non-malformed fetuses, as well as for our own untreated control data. Interestingly, the fetal weight of the fetuses prenatally exposed to $\mathrm{COX}$ inhibitors was significantly higher when compared with the untreated control group. However, the intrauterine growth retardation observed in rat fetuses with MD has been previously reported also in rabbits (18). Such findings were confirmed for other congenital anomalies, including diaphragmatic hernia, which, similar to VSDs and MDs, has been related to prenatal exposure to COX inhibitors (1719). It is worth mentioning that the incidence of MDs in the rat group exposed to aspirin was significantly higher when compared to other nonselective COX inhibitors ( $\mathrm{P}=$ $0.019)$, ibuprofen itself $(P=0.005)$, and selective COX-2 inhibitors ( $\mathrm{P}<0.0001)(16)$.

On the other hand, it has been proved that small VSDs induced by prenatal exposure to trimethadione did not significantly affect fetal viability or growth (7). Unlike all other COX inhibitor studies, the developmental effect was treatment-related. In the low dose group $(400 \mathrm{mg} / \mathrm{kg})$ the incidence and severity of VSDs were lower, and the septal anomalies were detected by the presence of blood flowing through the defect from the closed right ventricle. However, in the higher dose group $(600 \mathrm{mg} / \mathrm{kg})$ most of the VSDs were grossly visible. The incidence of VSDs decreased after birth from 7.6 to $0 \%$ and from 49.8 to $6.4 \%$ in groups exposed to 400 and $600 \mathrm{mg} / \mathrm{kg}$ trimethadione, respectively. As stressed by Fleeman et al. (7), similar to our findings, all defects were limited to the membranous part of the septum. Furthermore, other cardiac and large vessel anomalies occurred in the higher drug dose group. This may indicate even higher incidence of VSDs in COX-exposed fetuses since none of the studies applied the blood flow procedure. Comparable findings were also reported for fetal growth parameters. Although a treatment-related decrease of mean fetal weight 
was observed at both doses used, no statistically significant differences were found between fetuses with VSDs and non-malformed ones. No association between intrauterine growth retardation and VSDs was also observed by Solomon et al. (6), who found a similar incidence of malformations in control and in growth-retarded fetuses whose mothers were treated with a $25 \%$ restricted diet. The spontaneous postnatal closure of VSDs was also reported.

The primary mechanism underlying VSDs, MDs, diaphragmatic hernia (15-17), and skeletal anomalies $(15,16,24)$ has been associated with prenatal COX-1 blockade and disturbances in eicosanoid physiology. COX-1 is the only COX isoenzyme which was detected throughout the whole embryonic and fetal period, and could regulate prostaglandins, prostacyclin and thromboxane synthesis (35). COX-2 expression was revealed only in the skin, heart, cartilage, and kidney of fetuses aged $\geq 16$ GD (35) when interventricular septation was completed (36). The critical period for the ventricular septal development appears to be between GD 8 and 16. It includes development of the primordial endocardium (GD 8.25-8.5) from which the endocardial cushion originates (GD 13), and finally the formation of the membranous part of the ventricular septum (36).

A COX-1-dependent mechanism explains the high prenatal toxicity of aspirin. Aspirin, unlike other common NSAIDs, is an irreversible $\mathrm{COX}$ inhibitor which at low doses selectively blocks the COX-1 isoenzyme (18, 23). This mechanism also explains the good prenatal tolerance of COX-2 selective compounds, which induce only intrauterine growth retardation when administered at high doses. Retardation seems to be secondary to COX-2 inhibition in late pregnancy $(16,24)$. On the other hand, single cases of VSDs and gastroschisis were observed in fetuses treated in utero with very high dose of CJ-19,209 (19) and DFU (16), respectively. However, there was no information whether the COX2 selectivity level was exceeded. According to recent observations $(16,17,19)$, and since both compounds have a high COX-2 specificity ratio $(16,19)$, VSD and MD cases should be recognized as spontaneous events not related to COX-2 blockade. Further studies with other selective compounds are necessary to confirm their high prenatal safety, since the available data are insufficient for reliable statistical analysis. It should be mentioned that a similar effect, limited to the diaphragmatic hernia, was observed for celecoxib, which is the oldest COX-2 inhibitor available on the market (37). The defect was found in rat offspring prenatally exposed to a dose just six times higher than the human therapeutic one.

The animal findings were partially confirmed in human observations. The Swedish study (12) showed an increased prevalence of VSDs among children exposed to the nonselective drugs (diclofenac, ibuprofen, naproxen). A higher than expected incidence of congenital cardiac anomalies was also found in other studies $(1,14,38)$. However, contrary data were also reported $(2,9,11,13)$. In most of the studies, it was mentioned that the VSDs are associated with maternal fever, which was the main reason for taking the drugs $(9-11,13,14)$. On the other hand, hyperthermia itself may induce apoptosis and disturb septal development $(39,40)$.

We may conclude that prenatal exposure to COX inhibitors, especially aspirin and ibuprofen, increased the incidence of ventricular septal defects in rat offspring. More intensive studies, including evaluations of target organ toxicity, for other COX inhibitors are needed to estimate the risk of application of a specific compound rather than of the whole group of drugs.

\section{Acknowledgments}

The authors would like to thank all coworkers and friends who helped with the 
research and the project. We are particularly grateful to Merck Research Laboratories (Rahway, NJ, USA), Jelfa Jelenia Gora (Jelenia Gora, Poland) and Polfa Pabianice
(Pabianice, Poland) for providing DFU, piroxicam, and ibuprofen samples for the experiment.

\section{References}

1. Ferencz C, Loffredo CA, Correa-Villaseñor A, Wilson PD. Ventricular septal defects. In: Ferencz C, Loffredo CA, Correa-Villaseñor A, Wilson PD (Editors), Genetic and enviromental risk factors of major cardiovascular malformations: The Balimore-Washington Infant Study 1981-1989. Armonk: Futura Publishing Company, Inc.; 1997. p 123-163.

2. Cleves MA, Savell VH J r, Raj S, Zhao W, Correa A, Werler MM, et al. Maternal use of acetaminophen and nonsteroidal anti-inflammatory drugs (NSAIDs), and muscular ventricular septal defects. Birth Defects Res A Clin Mol Teratol 2004; 70: 107-113.

3. Williams LJ , Correa A, Rasmussen S. Maternal lifestyle factors and risk for ventricular septal defects. Birth Defects Res A Clin Mol Teratol 2004; 70: 59-64.

4. Chantepie A, Luksenberg S, Vaillant MC, Pottier J M, Magontier N, Despert $F$, et al. Evolution of ventricular septal defects. Relation to echocardiographic anatomy. Arch Mal Coeur Vaiss 1999; 92: 623628.

5. Miyake $T$, Shinohara $T$, Nakamura $Y$, Fukuda $T$, Tasato $H$, Toyohara $\mathrm{K}$, et al. Spontaneous closure of ventricular septal defects followed up from $<3$ months of age. Pediatr Int 2004; 46: 135-140.

6. Solomon HM, Wier PJ, Fish CJ, Hart TK, Johnson CM, Posobiec LM, et al. Spontaneous and induced alterations in the cardiac membranous ventricular septum of fetal, weanling, and adult rats. Teratology 1997; 55: 185-194.

7. Fleeman TL, Cappon GD, Hurtt ME. Postnatal closure of membranous ventricular septal defects in Sprague-Dawley rat pups after maternal exposure with trimethadione. Birth Defects Res B Dev Reprod Toxicol 2004; 71: 185-190.

8. Reamon-Buettner SM, Borlak J. TBX5 mutations in non-Holt-Oram syndrome (HOS) malformed hearts. Hum Mutat 2004; 24: 104.

9. Tikkanen J, Heinonen OP. Risk factors for ventricular septal defect in Finland. Public Health 1991; 105: 99-112.

10. Botto LD, Lynberg MC, Erickson J D. Congenital heart defects, maternal febrile illness, and multivitamin use: a population-based study. Epidemiology 2001; 12: 485-490.

11. Werler MM, Mitchell AA, Shapiro $S$. The relation of aspirin use during the first trimester of pregnancy to congenital cardiac defects. N Engl J Med 1989; 321: 1639-1642.

12. Ericson A, Kallen BA. Nonsteroidal anti-inflammatory drugs in early pregnancy. Reprod Toxicol 2001; 15: 371-375.

13. Nielsen GL, Sorensen HT, Larsen H, Pedersen L. Risk of adverse birth outcome and miscarriage in pregnant users of non-steroidal anti-inflammatory drugs: population based observational study and case-control study. BMJ 2001; 322: 266-270.

14. Kallen BA, Otterblad OP. Maternal drug use in early pregnancy and infant cardiovascular defect. Reprod Toxicol 2003; 17: 255-261.

15. Burdan F. Developmental toxicity evaluation of ibuprofen and tolmetin administered in triple daily doses to Wistar CRL:(WI)WUBR rats. Birth Defects Res B Dev Reprod Toxicol 2004; 71: 321-330.

16. Burdan F. Comparison of developmental toxicity of selective and non-selective cyclooxygenase-2 inhibitors in CRL:(WI)WUBR Wistar rats - DFU and piroxicam study. Toxicology 2005; 211: 12-25.

17. Cook J C, Jacobson CF, Gao F, Tassinari MS, Hurtt ME, DeS esso J M. Analysis of the nonsteroidal anti-inflammatory drug literature for potential developmental toxicity in rats and rabbits. Birth Defects Res B Dev Reprod Toxicol 2003; 68: 5-26.

18. Cappon GD, Gupta U, Cook J C, Tassinari MS, Hurtt ME. Comparison of the developmental toxicity of aspirin in rabbits when administered throughout organogenesis or during sensitive windows of development. Birth Defects Res B Dev Reprod Toxicol 2003; 68: 3846.

19. Cappon GD, Cook J C, Hurtt ME. Relationship between cyclooxygenase 1 and 2 selective inhibitors and fetal development when administered to rats and rabbits during the sensitive periods for heart development and midline closure. Birth Defects Res B Dev Reprod Toxicol 2003; 68: 47-56.

20. Olesen $C$, Steffensen FH, Nielsen GL, de J ong-van den Berg, Olsen $J$, Sorensen HT. Drug use in first pregnancy and lactation: a population-based survey among Danish women. The EUROMAP group. Eur J Clin Pharmacol 1999; 55: 139-144.

21. Tillett J, Kostich LM, VandeVusse L. Use of over-the-counter medications during pregnancy. J Perinat Neonatal Nurs 2003; 17: 3-18.

22. United Nations. Consolidated list of products whose consumption and/or sale have been banned, withdrawn, severely restricted or not approved by governments (ST/ESA/239-E.94IV.3). New York: United Nations Publication; 1994. p 138-139.

23. Dannhardt G, Kiefer W. Cyclooxygenase inhibitors - current status and future prospects. Eur J Med Chem 2001; 36: 109-126.

24. Burdan F, Dudka J, Szumilo J, Korobowicz A, Klepacz L. Prenatal effects of DuP-697 - the irreversible, highly selective cyclooxygenase-2 inhibitor. Reprod Toxicol 2003; 17: 413-419.

25. Burdan F, Siezieniewska Z, Kis G, Blicharski T. Embryofetotoxicity of acetaminophen (paracetamol) in experimental in vivo model. Ann Univ Mariae Curie Sklodowska [Med] 2001; 56: 89-94.

26. Burdan F. Somatic and skeleton development of rat foetuses following in utero exposure to isopropylantipyrine (propyphenazone) during the second trimester of gestation. Folia Morphol 2000; 59: 317322.

27. Burdan F. Intrauterine growth retardation and lack of teratogenic effects of prenatal exposure to the combination of paracetamol and caffeine in Wistar rats. Reprod Toxicol 2003; 17: 51-58.

28. Burdan F. Effects of prenatal exposure to combination of acetaminophen, isopropylantipyrine and caffeine on intrauterine development in rats. Hum Exp Toxicol 2002; 21: 25-31.

29. Burdan F. Developmental effects of propyphenazone in analgesic and antipyretic combination with caffeine or paracetamol. Hum Exp Toxicol 2004; 23: 235-244.

30. Burdan F, Szumilo J, Dudka J, Klepacz R, Blaszczak M, Solecki M, et al. Morphological studies in modern teratological investigations. Folia Morphol 2005; 64: 1-8. 
31. Developmental Toxicology. DevTOX pagE. 2006. http://www. devtox.org/nomenclature/organ.php. Accessed J une 27, 2005.

32. Shein-Chung $C$, J en-Pein L. Design and analysis of animal studies in pharmaceutical development. New York: Marcel Dekker; 1998.

33. Fritz $\mathrm{H}$. P renatal ossification in rabbits as indicative of fetal maturity. Teratology 1975; 11: 313-319.

34. Burdan F, Szumilo J, Dudka J , Korobowicz A, Klepacz R. Celosomy is associated with prenatal exposure to cyclooxygenase inhibitors. Pharmacol Res 2006; 53: 287-292.

35. Stanfield KM, Bell RR, Lisowski AR, English ML, Saldeen SS, Khan $\mathrm{KN}$. Expression of cyclooxygenase- 2 in embryonic and fetal tissues during organogenesis and late pregnancy. Birth Defects Res A Clin Mol Teratol 2003; 67: 54-58.

36. DeSesso J M. Comparative embryology. In: Hood RD (E ditor), Hand- book of developmental toxicology. New York: CRS Press; 1997. p 117-174.

37. Physician's Desk Reference (PDR). Release 2003.1AX. [CD-ROM] Montvale: Thomson PDR; 2003.

38. Briggs GG, Freeman RK, Yaffe SJ. Drugs in pregnancy and lactation: A reference guide to fetal and neonatal risk. Baltimore: Williams \& Wilkins; 1998.

39. Mirkes PE, Cornel LM, Park HW, Cunningham ML. Induction of thermotolerance in early postimplantation rat embryos is associated with increased resistance to hyperthermia-induced apoptosis. Teratology 1997; 56: 210-219.

40. Watanabe $M, J$ afri $A, F$ isher $S A$. Apoptosis is required for the proper formation of the ventriculo-arterial connections. Dev Biol 2001; 240: 274-288. 